\title{
Pyrocarbon Arthroplasty: An Innovative Alternative for Advanced Post-Traumatic Hamatometacarpal Arthritis
}

\author{
Quentin Baumann ${ }^{1 *}$, Céline Klein ${ }^{1}$,Emmanuel David ${ }^{1}$, Nicolas Lebeau ${ }^{2}$ and Mirdad Moughabghab ${ }^{2}$
}

${ }^{1} \mathrm{CHU}$ Amiens, Service Orthopédie, CHU Amiens Sud, 1 rue du Pr Christian Cabrol, 80000 Amiens, France

${ }^{2}$ SOS Mains, CH Saint Quentin, 1 Avenue Michel de I'Hospital, 02321 Saint-Quentin, France

\begin{abstract}
Background: Post-traumatic arthritis of the hamatometacarpal complex (HMC) is a very rare disease and it occurs as an early secondary effect to undiagnosed or non-well treated fractures or fracture/dislocations of the $5^{\text {th }}$ metacarpal basis. It frequently occurs to young patients and manual workers requiring an important strength and hand mobility.

Treatment is not consensual and ranges from medical management to intermetacarpal arthrodesis.

We propose an alternative technique: A pyrocarbon arthroplasty.

Hypothesis: The main objective was to assess the clinical and radiographical results of the pyrocarbon arthroplasty in the case of post-traumatic arthritis of the hamatometacarpal (HM) joint at a mean follow up of 20 months.

Methods: Between 2014 and 2016, we reported the case of 4 patients suffering from a post-traumatic HM arthritis. The population include 4 men, the average age was 41-years-old (35-51). The dorsal approach procedure was performed, then a $2 \mathrm{~mm}$ resection of the hamate and the $5^{\text {th }}$ metacarpal basis was performed, implant sizes (STPI Tornier, initially used for scaphotrapeziotrapezoid arthritis) were tried before setting up the definitive component. During the last followup, we assessed the pain (VAS pain score), DASH score, average grip strength on both hands patients satisfaction, and return to work time. On AP X-rays and stress views, we were assessed luxations, subluxations or osteoarthritis signs.

Results: With a mean follow-up of 20 months, the average VAS pain score was 2 (0-6), the average DASH was 8.75 (0-15) and the average grip strength was $69.75 \%$ (55-96) compared to the contralateral side.

All patients declared to be satisfied or very satisfied by the surgical procedure and the average return-to-work time was 2 months.

All patients were able to go back to their work without any professional reclassification.

No patients declared to have had postoperative complications.

Radiological examinations displayed a good position of the implant and no further evolution of carpometacarpal arthritis.

Conclusion: Pyrocarbon implant in case of hamatometacarpal arthritis is an easy and safe procedure which offered promising results concerning satisfaction, functionality and hand strength in young and manual-workers patients. The sample is small and previous studies about surgical solution for this disease are too heterogeneous to compare the different procedures. Preliminary results are satisfying. It could be an option to consider for patients with an advanced disease of this joint.
\end{abstract}

Level of evidence: III, retrospective study.

Keywords

STPI, Pyrocarbon, Hamatometacarpal arthritis, Carpometacarpal arthritis

\section{Introduction}

Hamatometacarpal fractures dislocations (HMFD) are rare disorders that affect $1 \%$ of hand trauma and are largely under-diagnosed [1-3]. Cain and Al have proposed a classification according to the severity and then describe therapeutic principles ranging from simple reduction by external maneuvers to open surgical reduction associated with osteosynthesis. Sequelae lead to a loss of axial length, a decrease in the grip strength and result in painful carpo-metacarpal osteoarthritis $[4,5]$. Even operated Papaloizos found
*Corresponding author: Q Baumann, CHU Amiens, Service Orthopédie, CHU Amiens Sud, 1 rue du Pr Christian Cabrol, 80000 Amiens, France

Accepted: March 28, 2020

Published online: March 30, 2020

Citation: Baumann Q, Klein C, David E, et al. (2020) Pyrocarbon Arthroplasty: An Innovative Alternative for Advanced Post-Traumatic Hamatometacarpal Arthritis. J Orthop Surg Tech 3(1):110-114

Copyright: (C) 2020 Baumann Q, et al. This is an open-access article distributed under the terms of the Creative Commons Attribution License, which permits unrestricted use, distribution, and reproduction in any medium, provided the original author and source are credited. 


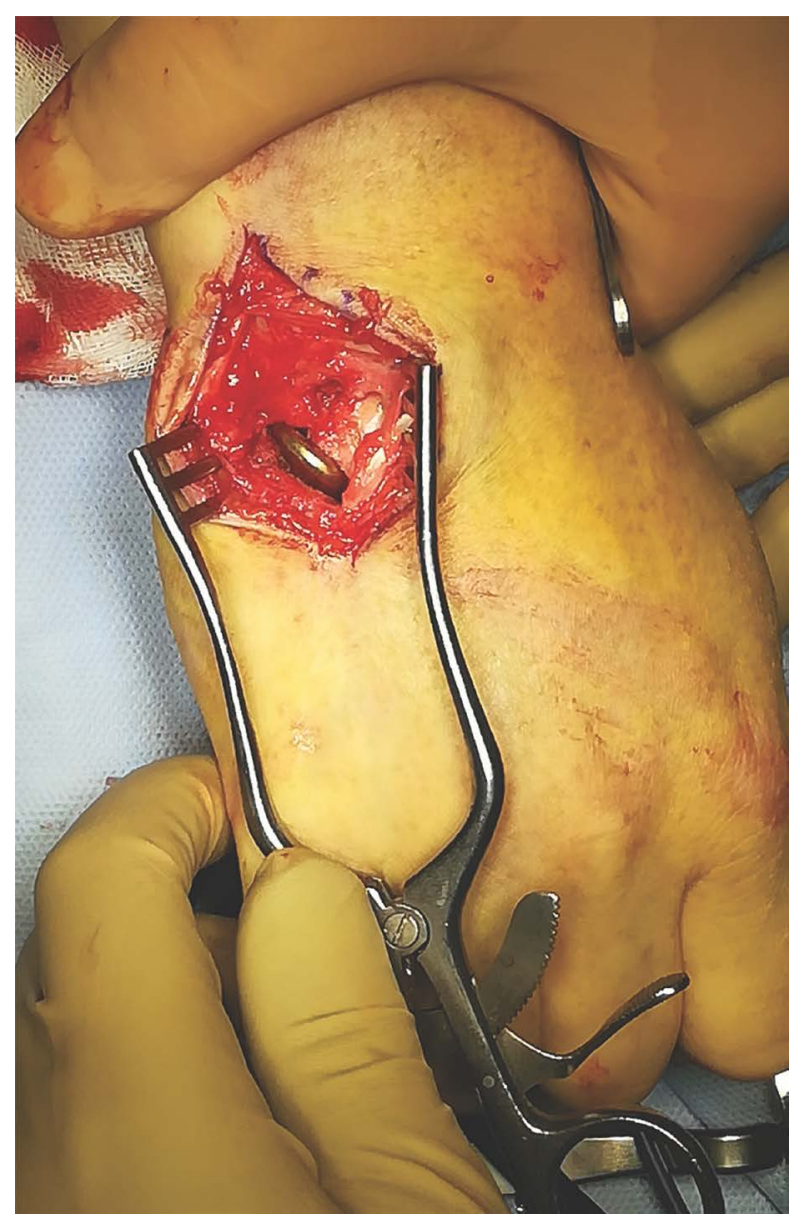

Figure 1: Intra-operative view of the implant.

$40 \%$ hamato-metacarpal arthritis in a retrospective series at 3 years [6]. Historically, these sequential lesions were surgically treated by HM arthrodesis. Recently Dubert [7-9] popularized a procedure involving arthroplastic resection of the $5^{\text {th }}$ metacarpal (M5) base and inter-metacarpal fusion of the bases of M4 and M5 restoring certainly the length of the $4^{\text {th }}$ and $5^{\text {th }}$ metacarpal but decreasing the rank of motion the fifth ray $[7,8]$. The "scaphoid trapezium pyrocarbon implant" type pyrocarbon implant (STPI) was initially developed to treat scapho-trapezo-trapezoidal arthritis [10-12] (Figure 1). It benefits of a Young's modulus close to the bone without adverse reaction of the neighboring tissues. This implant has a button shape with a concave face and another convex one that can reproduce the anatomy of the hamatometacarpal (HM) joint. We propose a therapeutic alternative to the Dubert technique in post-traumatic arthritis of the HM by pyrocarbon implant arthroplasty in order to restore both length and mobility as close as possible to anatomical conditions [13]. We want to describe this innovative technique and evaluate the early clinical and radiological results.

\section{Material and Methods}

\section{Participants}

Between 2014 and 2016, we report retrospectively four cases with severe HM arthritis M5 following a HMFD. The written consent of the patients was collected prior to the study. The patients were four men, all right-handed. The initial trauma mechanism was in all cases a direct trauma in the axis of the V-ray closed fist against a solid surface causing an articular fracture of the base of the fifth metacarpal (4 cases), associated with a fracture of the articular base of the IV metacarpal ( 2 cases) and a carpometacarpal dislocation of the $5^{\text {th }}$ ray ( 1 case) [14-18]. All patients were initially treated by emergency services in our area by immobilization in intrinsic position and associated with a closed reduction in 1 case. The surgical indication was considered in the presence of M5 base osteoarthritis, a high functional demand of the patient and six months of medical treatment including anti-inflammatories, analgesics, a nocturnal wrist orthosis and physiotherapy sessions.

\section{Surgical technique}

Surgery was performed in outpatient surgery under loco-regional anesthesia and pneumatic tourniquet by the same operator, a senior surgeon. The primary approach was an S-shaped longitudinal dorsal approach centered on the HM joint of the $5^{\text {th }}$ ray. The ulnar dorsal cutaneous sensory branch was identified, and the extensor tendons of the fifth ray were retracted. A transverse dorsal capsular incision of the hamatometacarpal joint was performed. Resection of the injured articular surfaces of the hamate and M5 base was performed using an oscillating saw on $2 \mathrm{~mm}$ on the metacarpal side and $2 \mathrm{~mm}$ on the hamate. The implant test was performed (Figure 1). After testing in flexion, extension, ulnar and forced radial inclination, the implant was put in place, the capsular plane was closed after washing and then a subcutaneous redon was left for a few hours. A flexible wrist orthosis was put in place for one month [19]. The patients were seen after one month with X-rays. The splint was removed and rehabilitation was started with self-rehabilitation instructions.

\section{Evaluation}

A short-term assessment at 6 month follow-up and a mid-term assessment at minimum 18 months follow up was performed by a single junior surgeon during a dedicated consultation. The clinical criteria included pain assessed on a visual analogue scale (VAS), the French version of the Disabilities of the Arm score, Shoulder and Hand (DASH) [20], the recovery time and the type of professional activity; clamping force to Jamar's dynamometer with respect to the opposite side [21]. Hypoesthesia of the ulnar area was assessed by a monofilament, as well as a subjective episode of instability. Patient satisfaction was appreciated by asking them how they rated the function of their hand: Much better improved (very satisfied); better (satisfied); identical; worse (unhappy). Preoperative and postoperative radiological analysis as well as the last follow-up included AP X-ray of the full face and profile of the wrist, as well as a tight fist X-ray allowing the assessment of osteoarthritis, the study of positioning and dislocation or subluxation of the implant.

\section{Results}

\section{Clinical results}




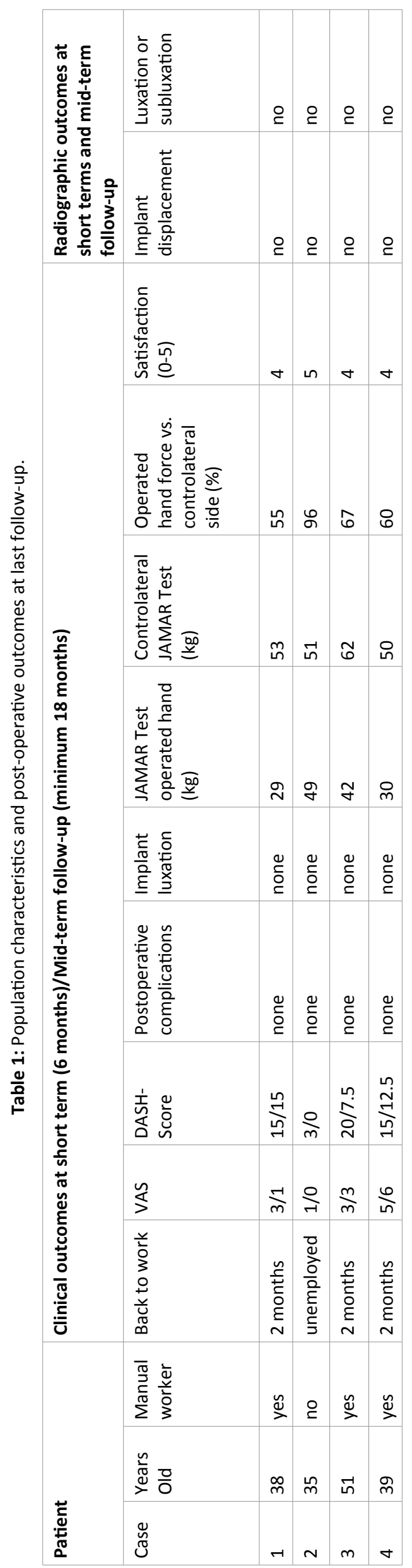

The mean follow-up of the mid-term assessment was 20 months. The mean age at the time of surgery was 41 years (35-51 y/o). The mean delay between initial trauma and arthroplasty was 32.2 months (17-51 y/o). We summarize the postoperative clinical results in Table 1 . All patients returned to the same professional activity at the end of the sick leave period initially prescribed after surgery ( 2 months) with the exception of one unemployed patient. Regarding the pain, the average VAS is $2 / 10(0-6)$, the average DASH score is calculated to be 8.75 (0-15), all the patients declared themselves satisfied or very satisfied, no hypoesthesia of the ulnar margin was found in the monofilament, and no episode of dislocation or instability was reported by patients. We also know that there was no immediate postoperative complication.

\section{X-ray results}

Preoperative radiographs showed HM osteoarthritis at M5 for 2 patients and hamatometacarpal osteoarthritis at M4 and $\mathrm{M} 5$ in 2 cases.

Radiological analysis at the last follow-up, showed that the implant was in place compared to the full-face postoperative (Figure $2 \mathrm{a}$ ) and profile (Figure $2 \mathrm{~b}$ ) postoperative radiographs in all patients. There was no hamatometacarpal osteoarthritis. The cliches in closed fist stress (Figure 2c) did not find dislocation or subluxation of the implant.

\section{Discussion}

The objective of the treatment of post-traumatic HM osteoarthritis is on the one hand to reduce the pain phenomena, to recover a clamping force and to restore an anatomy closest to the normal. We were able to show that the STPI implant meets these three objectives and that the clinical and radiological results on the medium-term are good; unlike HM arthrodesis, an effective technique to reduce painful phenomena, but that does not allow to recover the curve of the hand and the original mobility of the $\checkmark$ ray, essential elements to the "strength hand" and the "sharpness hand", and this is due to the decrease in the length of M5 and the mobility of the HM joint. Yang, Bain and Meraghini's studies of Dubert's intervention appeared to provide good clinical results and restore the length of M5, but give M5 the $4^{\text {th }}$ ray mobility segment $[7,9,22]$.

In addition, the role of "spacer" of the STPI implant allowed on the one hand to restore the height and on the other hand the absence of fixation associated with the interposition to restore the hamatometacarpal original mobility. In 1991, Gainor [23] proposed to perform an "anchovy" tendon interposition "anchovy" to restore the height and mobility on the short term, but this intervention required the sacrifice of the long palmar, and we do not know the long-term survival of the tendon in the joint.

One of the limiting points of this work is the small number of patients included as well as its retrospective nature. Although none of the published series has a large cohort, those described with the Dubert procedure by Bain and Meraghni respectively include five and six patients $[7,9]$. On the other hand, in the case of associated carpometacar- 


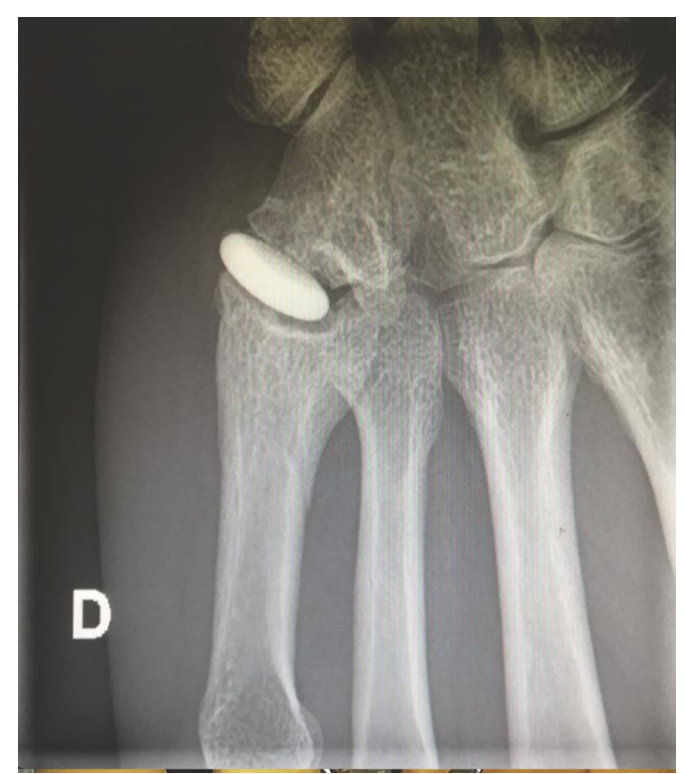

A

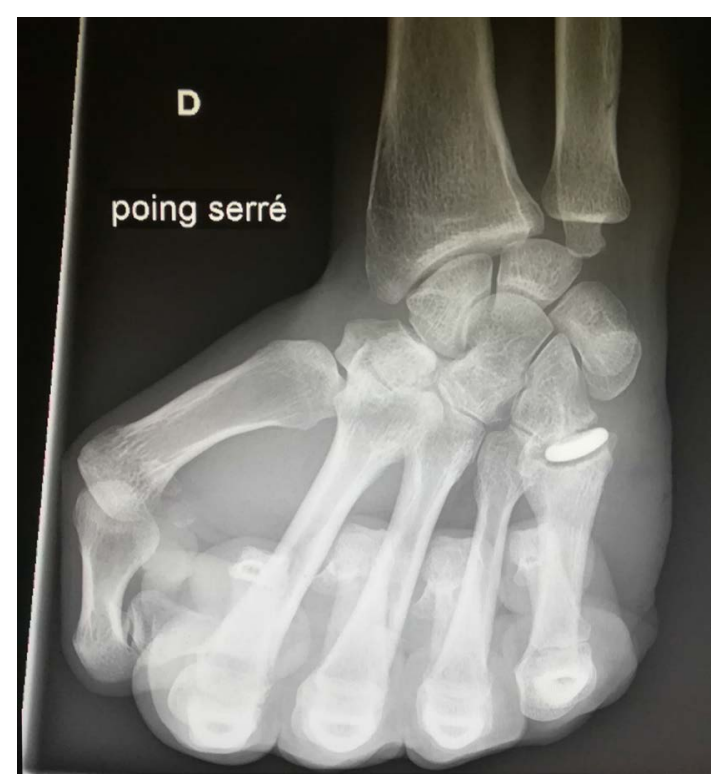

B

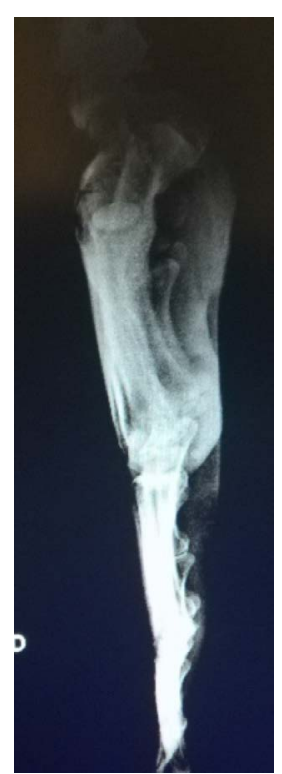

C

Figure 2: a) AP; b) Lateral; c) Stress closed fist post-operative X-ray for patient A at 23 months follow up.

pal arthritis of the $4^{\text {th }}$ ray, it is possible to imagine that the results would be worse than the existing osteoarthritis. It would be interesting to carry out a study involving a larger number of patients, and to be able to distinguish between patients with and without associated involvement of the fourth CMC joint for whom the Dubert procedure is not recommended [7].

It is also noted that the two patients with the most pain also had arthritic sequelae in the $4^{\text {th }} \mathrm{CMC}$. Moreover, it is difficult to compare the results with those of the Dubert series on series of this size, but the results tend to be comparable. Thus, this intervention is a useful and simple alternative in the therapeutic arsenal, which does not compromise a more invasive gesture.

\section{Conclusion}

HM stent arthroplasty STPI is a reliable, simple and reproducible surgical technique. It can be offered as first-line treatment for painful HM osteoarthritis since it preserves the bone mass and does not prevent subsequent arthrodesis.

The authors declare that they have no conflict of interest.

\section{References}

1. Gilula LA (1979) Carpal injuries: Analytic approach and case exercises. AJR Am J Roentgenol 133: 503-517.

2. Gangloff D, Mansat P, Gaston A, et al. (2007) Les luxations carpométacarpiennes du cinquième rayon: Etude descriptive à propos de 31 cas. Chirurgie de la Main 26: 206-213.

3. Henderson JJ, Arafa MA (1987) Carpometacarpal dislocation. An easily missed diagnosis. J Bone Joint Surg Br 69: 212-214.

4. Hunt TR (2006) Degenerative and post-traumatic arthritis affecting the carpometacarpal joints of the fingers. Hand Clin 22: 221228.
5. Fisher MR, Rogers LF, Hendrix RW (1983) Systematic approach to identifying fourth and fifth carpometacarpal joint dislocations. AJR Am J Roentgenol 140: 319-324.

6. Papaloizos MY, Le Moine P, Prues-Latour V, et al. (2000) Proximal fractures of the fifth metacarpal: A retrospective analysis of 25 operated cases. J Hand Surg Br 25: 253-257.

7. Meraghni N, Bacle G, Marteau E, et al. (2017) Results of the Dubert procedure for chronic painful fracture-dislocations of the fifth carpometacarpal joint. A report of 6 cases. Hand Surg Rehabil 36: 373-377.

8. Dubert T (1994) Arthroplastie stabiliséedu cinquième métacarpien proposition thérapeutique pour le traitement des fractures-luxations anciennes du 5 e métacarpien. Annales de Chirurgie de la Main et du Membre Supérieur 13: 363-365.

9. Bain GI, Unni PMR, Mehta JA, et al. (2004) Arthrodesis of ring finger and little finger metacarpal bases for little finger carpometacarpal joint arthritis. J Hand Surg Br 29: 449-452.

10. Pegoli L, Zorli IP, Pivato G, et al. (2006) Scaphotrapeziotrapezoid joint arthritis: A pilot study of treatment with the scaphoid trapezium pyrocarbon implant. J Hand Surg BR 31: 569-573.

11. Marcuzzi A, Ozben H, Russomando A (2014) Treatment of scaphotrapezial trapezoidal osteoarthritis with resection of the distal pole of the scaphoid. Acta Orthop Traumatol Turc 48: 431436.

12. Iniesta A, Gay A, Corcella D, et al. (2014) Résultats à moyen terme de l'utilisation de l'implant en pyrocarbone STPI dans la prise en charge de l'arthrose scapho-trapézo-trapezoïdienne. Chirurgie de la Main 33: 436-437.

13. Meunier MJ, Hentzen E, Ryan M, et al. (2004) Predicted effects of metacarpal shortening on interosseous muscle function. J Hand Surg AM 29: 689-693.

14. Liaw Y, Kalnins G, Kirsh G, et al. (1995) Combined fourth and fifth metacarpal fracture and fifth carpometacarpal joint dislocation. J Hand Surg Br 20: 249-252. 
Citation: Baumann Q, Klein C, David E, et al. (2020) Pyrocarbon Arthroplasty: An Innovative Alternative for Advanced Post-Traumatic Hamatometacarpal Arthritis. J Orthop Surg Tech 3(1):110-114

15. Athanasiou V, Iliopoulos ID, Pantazis K, et al. (2017) Fracture of the body of the hamate with dorsal dislocation of the $4^{\text {th }}$ and $5^{\text {th }}$ metacarpals: A case report. Open Orthop J 11: 447-451.

16. Eichhorn-Sens J, Katzer A, Meenen NM, et al. (2001) Carpo-metacarpal dislocation injuries. Handchir Mikrochir Plast Chir 33: 189.

17. Storm JO (1988) Traumatic dislocation of the fourth and fifth carpo-metacarpal joints: A case report. J Hand Surg Br 13: 210-211.

18. Lundeen JM, Shin AY (2000) Clinical results of intraarticular fractures of the base of the fifth metacarpal treated by closed reduction and cast immobilization. J Hand Surg Br 25: 258-261.

19. Roger C, Moughabghab M, Rotari V, et al. (2015) Arthrose carpo-métacarpienne post-traumatique des $4^{\mathrm{e}}$ et $5^{\mathrm{e}}$ rayons de la main - technique chirurgicale de l'arthroplastie par implant en pyrocarbone. Chirurgie de la Main 34: 393.

20. Dubert T, Voche P, Dumontier C, et al. (2001) The DASH questionnaire. French translation of a trans-cultural adaptation. Chir Main 20: 294-302.

21. Wichelhaus A, Harms C, Neumann J, et al. (2018) Parameters influencing hand grip strength measured with the manugraphy system. BMC Musculoskelet Disord 19: 54.

22. Yang Y, Scheker LR, Kumar KK (2015) Arthroplasty for fifth carpometacarpal joint arthritis. J Wrist Surg 4: 110-114.

23. Gainor BJ, Stark HH, Ashworth CR, et al. (1991) Tendon arthroplasty of the fifth carpometacarpal joint for treatment of posttraumatic arthritis. J Hand Surg Am 16: 520-524.

DOI: $10.36959 / 453 / 531$

Copyright: (C) 2020 Baumann Q, et al. This is an open-access article distributed under the terms of the Creative Commons Attribution License, which permits unrestricted use, distribution, and reproduction in any medium, provided the original author and source are credited. 